\title{
Determining Measures Enhancing Bridges Maintenance Practice in Nigeria
}

\author{
Isa Sani Mohammed ${ }^{1}$, Anas Muhammad ${ }^{2}$, Bashir Mohammed ${ }^{1, *}$ \\ ${ }^{1}$ Department of Civil Engineering, Nigerian Defence Academy, Kaduna State, Nigeria \\ ${ }^{2}$ Department of Quantity Surveying, Kaduna Polytechnic, Kaduna State, Nigeria
}

Received November 7, 2019; Revised December 31, 2019; Accepted May 13, 2020

Copyright $\bigcirc 2020$ by authors, all rights reserved. Authors agree that this article remains permanently open access under the terms of the Creative Commons Attribution License 4.0 International License

\begin{abstract}
A number of bridges, across the globe, have suffered from poor maintenance. This has caused cracks and other forms of deterioration resulting to untimely failure of the bridge structure thereby impairing its safety. That is attributed to limited number of accurate and economical techniques and measures hindering the enhancement of the bridges maintenance practice particularly in Nigeria. This study assesses bridges maintenance practice within Kaduna and Zaria based on the following objectives: the identification of the concepts of bridges maintenance practice, examination of the measures enhancing bridges maintenance practice within Kaduna and Zaria metropolis and the determination of suitable measures that enhance bridges maintenance practice. A total of one hundred and fifty (150) questionnaires were administered to maintenance personnel of state and federal government agencies, consultants and contractors that are involved with bridges maintenance. Ninety-two (92) valid questionnaires were returned representing $61.33 \%$ valid response rate, and subsequently analyzed by using descriptive and inferential statistics with the aid of Statistical Package for Social Sciences (SPSS) software. The study determines the following: inventory, condition, need and damage assessments, reliability and technical feasibility, funding and allocation, considerations of risks involved with any damages in safety and scheduling and programming among others as the most suitable measures enhancing bridges maintenance practice within Kaduna and Zaria metropolis. The thirty-two (32) Bridge Maintenance Measures (BMM), based on global best practices, in order of their suitability as rated in the study will enhance the practice. The suitable measures determined in this study have the potential for enhancing bridges maintenance practice towards achieving safety, cost, quality, amongst others.
\end{abstract}

Keywords Bridges, Bridges Maintenance, Bridges Maintenance Practice, Bridges Maintenance Measures

\section{Introduction}

Mature economies face the challenge of maintaining and modernizing critical infrastructure such as transport, power, water, and telecommunications (Council for International Business, 2014). Furthermore, developing and emerging economies continue to grapple with planning infrastructure to deliver basic human needs, including transport, water, sanitation, and electricity among others.

Transportation authorities across the world undertake enormous efforts to maintain transportation networks and aging bridges because of increases in traffic. The US Federal Highway Administration (FHWA) spent \$12.8 billion in 2013 for bridge maintenance (ASCE, 2013). England spent $£ 4$ billion in 2012-13 for maintaining the road network (Department for Transport and Highways Agency, 2014). At the same time, there is an urgent need for greater monetary resources to ensure reliable structural inspection and proper bridge maintenance. The FHWA estimates the required maintenance investment to be $\$ 20.5$ billion annually to eliminate the deficient bridge backlog by 2028 in the United State. Currently, only $\$ 12.8$ billion are spent (ASCE, 2013). McKinsey estimates the funding gap for road and rail in the UK to be around $£ 100$ billion between 2010 and 2030 (McKinsey \& Company, 2011). In contrast, the UK Department for Transport proposed cutting annual road maintenance budgets by $£ 1.2$ billion (Department for Transport and Highways Agency, 2014). The developing countries such as Nigeria also faced this challenge of funding bridges maintenance and rehabilitation across the country. Following that, Federal Government of Nigeria planned to spend N270 billion for maintenance, repairs and restoration of over fifty (50) bridges across the country (Nwannekanma \& Gbonegun, 2017).

Strategies have been developed to prioritize among various maintenance needs with the objective of maximizing value for money on critical infrastructure such as roads and bridges (London Bridges Engineering Group, 2008). Prioritization processes generally include the relevance of a structure for a road network, and its condition 
for assessing safety risks for bridge users and impact on the lifecycle of a structure. Bridges do not usually fail due to inadequate load capacity, but due to fatigue and/or corrosion cracking as most deterioration can be attributed to lack of proper maintenance (Osumeje, 2016). When bridge superstructures fail, it is sometimes due to excessive deterioration by inadequate load capacity or in efficient maintenance practice.

Several studies have highlighted the extent of decay and decline in the Nigerian infrastructure (Izuwah, 2017; Chima $\&$ Ekeghe, 2017). A number of bridges have suffered from poor maintenance, which has caused cracks and deterioration leaving steel rebar in most cases exposed to climatic conditions. Such exposure of rebar result in corrosion and in the untimely failure of the structure or thereby impairing its safety conditions (Azmera, 2013). The failure of a bridge can be catastrophic as it can cause injury or death as well as being be very expensive to restore. Some of these bridges are structurally deficient or functionally obsolete and some have even been shut to traffic due to heavy traffic usage and low maintenance attitude which have characterized most bridges (Osumeje, 2016).

Presently only a limited number of accurate and economical techniques, and measures exist to test these structures for integrity and safety as well as ensure that they meet original design specifications (Weil \& Gary, 1998; Kirk, Robert, Mallett \& William, 2018).

Decades of neglect have resulted in colossal damage to the Nigeria's bridges with many of them never undergoing any form of maintenance, either structured or unstructured over the last four to five decades (Nwannekanma and Gbonegun, 2017). They further asserted that the challenge with bridges maintenance and rehabilitation is not limited to funding, but in appropriate policy by the government to change the status quo. And this policy is normally drive by some measures and techniques that enhance the bridges maintenance practice. Several studies have identified challenges with existing bridge maintenance inspection as well as an overview on proposed methods to overcome these challenges (Philipp Hüthwohl, Ruodan Lu, Ioannis \& Brilakis, 2016; Nwannekanma \& Gbonegun, 2017).

In general, limited number of accurate and economical techniques, and measures are hindering the enhancement of the bridges maintenance practice particularly in Nigeria. So in view of the foregoing, it is imperative to determine more measures that will enhance the practice. Also, previous studies have not considered the perspective of these key stakeholders (maintenance personnel of state and federal government agencies, consultants and contractors) involved with bridges maintenance, repair and restoration within Kaduna and Zaria metropolis as the research population. Hence, assessing measures that will enhance bridges maintenance practice will help in determining suitable measures that will promote the overall maintenance culture based on global best practices. However, this research intends to fill in this gap. Thus, this study seeks to assess bridges maintenance practice within Kaduna and Zaria metropolis.

\section{Literature Review}

\subsection{Introduction}

Transportation is important to the flow of people and goods for healthy economy. The highway network becomes critical in terms of hazard events for evaluation and afterwards for response and recovery (Duwadi, Lance, Ralls \& Ralls, 2008). In recent times, bridge asset management and maintenance is getting serious attention like never before which has focus more on careful assessments of the long stayed problems and provision of an urgent action to establishing bridge database, updating, and inspection, prioritization for rehabilitation or maintenance. Maintenance and repair are work needed to preserve the intended load carrying capacity of the bridge to ensure correct functioning, aesthetic appearance and continued safety (Maintenance Guide, 2014).

Bridges are amongst the largest, most expensive and complex structures, which makes them crucial and valuable transportation asset for modern infrastructure. Bridge inspection is a crucial component of monitoring and maintaining these complex structures. It provides a safety assessment and condition documentation on a regular basis, noting maintenance actions needed to counteract defects like cracks, corrosion and spalling (Philipp Hüthwohl, Ruodan Lu, Ioannis Brilakis, 2016).

Bridge is defined as a structure, including supports, erected over depression or an obstruction, such as water, highway or railway, having a track or passage way for carrying traffic of other moving loads (Departments of Army and Air force Washington D.C., 1994). Bridges are key elements in the roads network and constitutes a major capital investment of nation's resources (King, 2016). Bridges are complex structures that are constantly exposed to adversities like changing temperatures, moisture, and dynamic loading. This makes them difficult to inspect. A comprehensive study on the reliability of manual inspection has identified significant drawbacks regarding completeness and objectivity (Phares et al., 2004). Bridge inspectors gave, on average, four-to-five different condition ratings. Assuming the reference condition rating to be correct, $58 \%$ of individual ratings were assigned incorrectly (Moore et al., 2001).

\subsection{Bridge Preventive Maintenance Plans (BPMP)}

The importance of the Bridge Preventive Maintenance Plan (BPMP) is to extends the life of bridges by identifying and performing qualifying maintenance activities approved by relevant Highway Administration Agencies and some international bodies around the globe such as the Federal High-Way Administration (FHWA), United States; Highways Department (HyD) of the Highways Department (HyD) of the Hong Kong Special Administration Region (HKSAR); International Association for Bridge Maintenance and Safety (IABMAS) based in Germany and Spain; and Transport Research Board New York, that are considered preventive maintenance (Wong et al. 2001; 
Haardt, 2002; Transport Research Board, 2008; Fredericks, 2016).

\subsubsection{Bridge Preventive Maintenance Measures}

a. Deck treatments

b. Deck asphalt replacement

c. Repairing, restoring, or strengthening of major structural elements

d. Retrofit of fatique-prone steel girders

e. Replacement of deteriorated bridge supports

f. Spot painting of steel elements

g. Other works that can be shown to improve the life of the bridge

The process starts with making sure files are up to date with the latest bridge inspection reports, because inspection coding system directly relates to the type of work the program will fund.

The ultimate goal of preventive maintenance is to keep those very expensive replacement projects as in the future as possible.

\subsection{Bridge Performance Measures (BPM)}

Performance measures are essential components of effective and efficient bridge management and maintenance practice as can be seen below;

a. Facilitates improvements of condition and services

b. Show tangible results to our customers and stakeholders

c. A tool for straightening accountability

d. A tool to assess the effectiveness of allocated resources

The figure 1 is a bridge maintenance cycle which is based on some measures enhancing bridge maintenance practice

\subsection{Contributing Factors to Strong Bridge Performance}

A. Make the case for bridge investment

a. Establish and use performance measures for benchmarking bridge conditions and communicating agency targets

b. Determine funding requirements to meet performance targets

c. Documents agency appropriate projects and to improve accountability

B. Emphasizing Bridge Preservation

a. Inspect bridges at the elements level

b. Track bridge-level work recommended actions as part of bridge inspections, and establish an approach to tracking and prioritizing rehabilitation and replacement work to ensure funds

c. Establish programs for common types of preservation actions such as bridges washing, joint repairs, deck overlays, painting and concrete repairs.

C. Construct Maintenance Bridges

a. Discourage the use of high maintenance design details i.e. eliminating expansion joints when possible

b. Encourage the use of standard designs-institutionalizing maintainable bridges design to reduce time and cost for engineering

c. Take advantage of alternative contracting and delivery approaches such as design/build and accelerated bridge construction

d. Enhance communications between bridge design and maintenance staff through quarterly or annual meetings

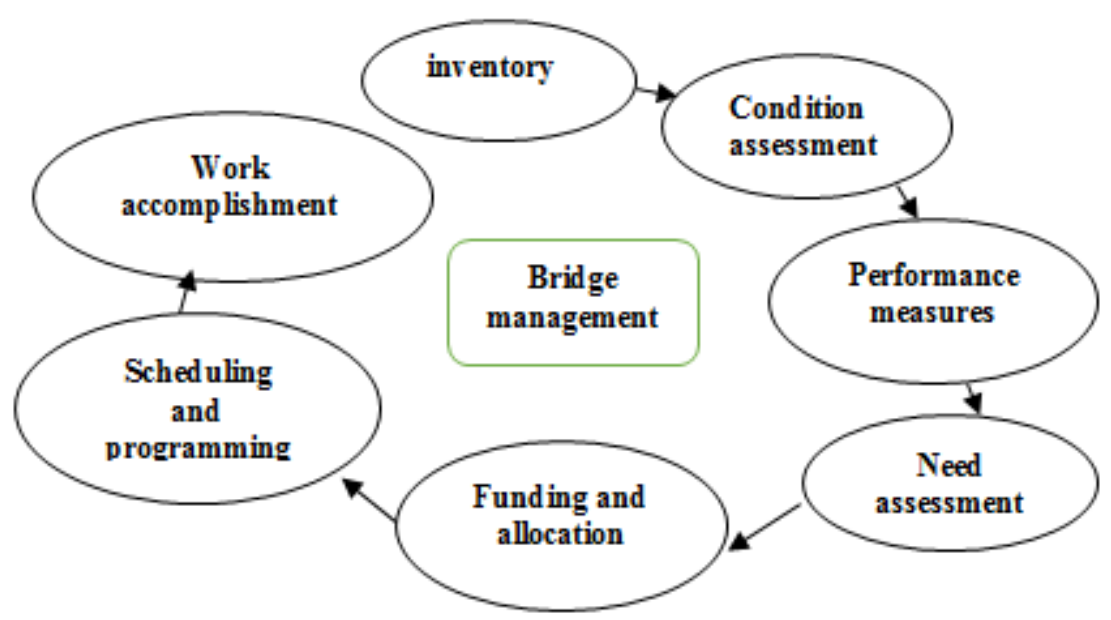

Figure 1. Bridge Maintenance Cycle 


\subsection{Guidelines for Inspection, Maintenance and Rehabilitation of Concrete Bridges}

\subsubsection{Rehabilitation of Concrete Bridges}

After completion and commissioning of the bridge, various operations that may be required to do on it are:

a. Maintenance and repair: These are the work needed to preserve the intended load carrying capacity of the bridge to ensure correct functioning, aesthetic appearance and continued safety.

b. Rehabilitation: This activity is larger in scope and cost. It is aim at restoring the bridge to its original service level it once had and has now lost. Aging, weathering, inadequacies in the design, detailing and defects during construction, damage due to external causes like; accidents, earthquakes, floods etc. foundation settlement, change in live load pattern during services.

c. Improvements: The aim of upgrading the level of service of a structure improvement can be for; increasing the load carrying capacity, changing geometric parameters like increasing in deck width etc.

d. Replacement or reconstruction: These works are required to be carried out when the whole structure or at least its major components are required to be replaced, being beyond the economic level of repairs/rehabilitation.

\subsection{Bridge Management Systems (BMSs)}

In the past 2 decades, the relationships between bridge conditions and rehabilitation decisions have begun to be formalized in the form of BMSs. A BMS is an integrated collection of the following elements:
a. Organizational roles
b. Procedures
c. Data Analytical tools
d. Computer programs
e. Support services

BMSs can be used to accomplish the following tasks:

a. Determine bridge needs.

b. Optimize funding allocation and project scheduling with budget constraints.

c. Develop persuasive funding requests.

d. Perform what-if analyses and policy analysis.

e. Monitor bridge condition.

\subsection{Summary}

Maintenance of today's bridge infrastructure presents many challenges. Presently, only a limited number of accurate and economical techniques and measures exist to test these structures for integrity and safety as well as ensure that they meet original design specifications. The approach to bridge maintenance is increasingly influenced by emerging factors, measures and management systems.

Other trends that will probably influence future developments and practices in this field include increased attention to life-cycle cost analyses and the incorporation of user costs into maintenance decisions. Certainly, bridge maintenance engineers will use an array of increasingly sophisticated instruments, procedures, and systems to evaluate, repair, and rehabilitate structures.

\subsection{Gap/Outstanding Issue}

Some of the bridge maintenance concepts identified in this study such as electrochemical debonding paint via low-voltage direct current, plasma jet, ablating paint without distressing substrate, technologies for the removal of existing coatings, bioingestion, using paint-eating bacteria, technologies for the removal of existing coatings, abrasives blasting, quadricon system, among others are not feasible or applicable to Nigeria specifically in Kaduna and Zaria due to technological, economic, environment, political and other reasons.

Some studies have also identified challenges with existing bridge maintenance inspection as well as an overview on proposed methods to overcome these challenges in both developed and developing countries (Philipp Hüthwohl, Ruodan Lu, Ioannis Brilakis, 2016; Nwannekanma and Gbonegun, 2017). In a nutshell, limited number of accurate and economical techniques and measures are hindering the enhancement of the bridges maintenance practice specifically in the developing countries such as Nigeria.

\section{Research Methodology}

\subsection{Research Approach}

A quantitative research approach was employed using questionnaire survey for this study. Quantitative research deals with the collection and analysis of data in numeric form or nature (Hughes, 2006). The questionnaire survey helped in getting the needed data for the purpose of actualizing the research objectives by evaluating the data using suitable statistical analytical tools.

Fellows and Liu (1999) stated that quantitative research approach is suitable for collecting data and in examining relationships between facts and help in linking those facts with theories and findings of any research carried out. It deals with measurable and quantifiable issues under research. Furthermore, it also deals with aspects for the measurement of quantity and amount (Eboh, 2009). Quantitative research approaches used scientific techniques to obtain measurements (quantified data) from social surveys such as; questionnaires, interview surveys, telephone survey etc. Lastly, reason of adopting quantitative research approach was to help in achieving the research objectives.

\subsection{Data Collection Method}

In order to achieve the aim of this research, data was collected via the following:

\section{Literature review:}

The research first started with the review of relevant 
literature. Specifically, extensive literature review on bridge maintenance concepts was carried out. This was done purposely to compile the list of Bridge Maintenance Measures (BMM) established around the globe (Highways Department (HyD) of the Hong Kong Special Administration Region (HKSAR) 2006; Transport Research Board, 2008: Ahmad, 2010; Fredericks, 2016; Indian railways publication, 2016; Hampshire country, 2015; United States Department of Transportation Publication, 2008; The IABMAS Bridge Management Commission, 2014; United States of Transportation Publication, 2012; Federal Highway Administration (FHWA) Publication, 2016).

The review focused on primary sources of data such as journal articles and conference papers.

Based on the literature reviewed, lists of thirty-two (32) measures were found to be significant in enhancing bridge maintenance practice. The thirty-two (32) Bridge Maintenance Measures (BMM) compiled were used to design a structured questionnaire that was used in collecting data from the field.

\section{Questionnaire survey}

Having identified the measures that enhance the bridges maintenance practice generally, the measures identified were used to construct a structured questionnaire used for field survey. The questionnaire survey assessed the measures enhancing bridge maintenance practice. Naom (1998), Enshassi et al. (2010) stated that the questionnaire is a widely used approach for descriptive and analytical surveys to find out the facts, opinions and views of respondents. Questionnaires are structured in a precise and concise way in order to avoid ambiguity and checked for expression. Another reason for chosen questionnaire survey is because it offers researchers the opportunity to reach a large number of potential respondents in different locations (Russell, 2006). In general, questionnaire survey helps in collecting information on facts, activities, level of knowledge, opinions, expectations and aspirations, membership of various groups, and attitudes and perceptions relevant to the study (Siniscalco and Auriat, 1998).

\subsection{Population of the Study}

The population of this study consists of three categories of respondents namely; maintenance personnel of the state and federal government agencies, consultants and contractors that are involved in bridges maintenance, repair and restoration.

Samples was drawn from the target population to get the desired information in assessing the measures enhancing bridges maintenance practice within Kaduna and Zaria metropolis.

\subsection{Sample}

Inferences about the population was made on the basis of a properly designed and well selected sample. Samples are usually drawn with the aim of estimating the population parameters. Some units are selected from the entire units of the population. In this case, the selected units are called the sample size.

\subsection{Sample Size Determination}

The determination of sample size is a common task for many empirical researchers. Inappropriate, inadequate, or excessive sample sizes continue to influence the quality and accuracy of research. A formula for selecting the sample size for a research problem based on a level of significance and a chosen margin of error was proposed by (Cochran, 1977; Levy \& Lemeshow, 2008). In order to obtain the most efficient, representative sample, for the research, the study used the following Cochran's formula for sample size determination.

$$
n=\left(\frac{Z_{\alpha / 2}}{2 \delta}\right)^{2}
$$

Where $n=$ Sample size to be determined $\delta=0.08$ (The chosen margin of error for the survey),

The value of the standard normal ordinate at $\alpha \%$ level of significance is $Z_{\alpha / 2}$,

At the $5 \%$ level of significance $Z_{\alpha / 2}=Z_{0.025}=1.96$.

The sample size is finally determined as follows.

$$
n=\left(\frac{Z_{\alpha / 2}}{2 \delta}\right)^{2}=\left(\frac{1.96}{2 \times 0.08}\right)^{2}=150
$$

That is, we need a sample size of at least 150 to arrive at a sample with a sampling error of at most $8 \%$.

\subsection{Stratified Random Sampling}

Stratified random sampling was used in determining of the sample size. This is because the population of the study is not known. In stratified random sampling, the population units are divided into a number of strata. Samples of predetermined sizes are drawn independently from each stratum by simple random sampling. Since a stratified random sampling consists of units selected separately from each stratum (respondents category), such a sample is expected to be better representation of the population (Levy \& Lemeshow, 2008). The following table summarizes the sample allocation in this stratified random sampling:

Table 1. Sample Sizes in Each Stratum

\begin{tabular}{|c|c|}
\hline Strata (Type of Respondents) & $\begin{array}{c}\text { Sample } \\
\text { size }\end{array}$ \\
\hline $\begin{array}{c}\text { Maintenance personnel of the state and federal } \\
\text { government agencies }\end{array}$ & 50 \\
\hline Consultants & 50 \\
\hline Contractors & 50 \\
\hline Total & 150 \\
\hline
\end{tabular}




\section{Results}

\subsection{Identification of Bridge Maintenance Measures (BMM)}

The first objective of this research is to identify measures that enhance bridges maintenance practice. Through extensive review of literature, a total of thirty- two (32)
Bridge Maintenance Measures (BMM) categorized into four factors were identified. Table 2 shows the list of the Bridge Maintenance Measures (BMM) compiled.

Table 2 shows how the bridges maintenance measures are categorized into four (4) stages namely preliminary considerations, making the case for bridge investment, bridge preservation and construct maintenance used in the practice.

Table 2. Bridge Maintenance Measures (BMM)

\begin{tabular}{|c|c|}
\hline BMM factors & Bridge Maintenance Measures (BMM) \\
\hline Preliminary considerations & $\begin{array}{l}\text { Inventory } \\
\text { Condition assessment/ Need assessment/ Damage Assessment. } \\
\text { Reliability and technical feasibility. } \\
\text { Funding and allocation. } \\
\text { Scheduling and programing/ Time involved in implementing the repair plan. } \\
\text { Assessment of estimated remaining life of structure. } \\
\text { Assessment of life expectancy anticipated for various available options. } \\
\text { Considerations of risk involved with any damages in safety level or reduction in load carrying } \\
\text { capacity. } \\
\text { Considering availability and efficacy of repair materials and equipment } \\
\text { Feasibility of having long duration traffic blocks }\end{array}$ \\
\hline $\begin{array}{l}\text { Making the case for bridge } \\
\text { investment }\end{array}$ & $\begin{array}{l}\text { Determination of funding requirements to meet performance targets. } \\
\text { Cost of repairs/rehabilitation for both short term and long term. } \\
\text { Documents agency appropriate projects and to improve accountability } \\
\text { Using of system(s) for measuring bridge performance. } \\
\text { Establishment and usage of performance measures for benchmarking bridge } \\
\text { conditions and communicating agency target }\end{array}$ \\
\hline Bridge Preservation & $\begin{array}{l}\text { Inspection of bridges at the elements level } \\
\text { Laying of temporary diversion and access for repairs, Tracking of bridge- } \\
\text { level work recommended actions as part of bridge inspection } \\
\text { Tracking and prioritizing rehabilitation and replacement work to ensure funds } \\
\text { Setting of programs for common types of preservation actions such as bridges washing, joint repairs, } \\
\text { deck overlays, painting and concrete repairs. }\end{array}$ \\
\hline Construct Maintenance Bridges & $\begin{array}{l}\text { Establishment of the level and frequency of maintenance. } \\
\text { Enhancing load capacity. } \\
\text { Usage of reporting and bridge management systems. } \\
\text { Availability of expert supervision during implementation. } \\
\text { Using of robust techniques in implementing maintenance plans. } \\
\text { Using of resilient techniques and materials to environmental changes } \\
\text { Employing Automated Visual Inspection. } \\
\text { Adoption of proven technology and new ideas. } \\
\text { Discouraging of the use of high maintenance design details i.e. eliminating expansion joints when } \\
\text { possible. } \\
\text { Use of standard designs-institutionalizing maintainable bridges design to reduce time and cost for } \\
\text { engineering. } \\
\text { Alternative contracting and delivery approaches such as design/build and accelerated bridge } \\
\text { construction. } \\
\text { Enhancing communications between bridge design and maintenance staff through quarterly or annual } \\
\text { meetings. }\end{array}$ \\
\hline
\end{tabular}

Source: (Highways Department (HyD) of the Hong Kong Special Administration Region (HKSAR), 2006;

Ahmad, 2010; Transport Research Board, 2008; Fredericks, 2016; Indian railways publication, 2016; Hampshire County, 2015; United States Department of Transportation Publication, 2008; The IABMAS Bridge Management Commission, 2014; United Stated of Transportation Publication, 2012; Federal Highway Administration (FHWA) Publication, 2016;). 


\subsection{Survey Results}

\subsubsection{Responses}

A total of one hundred and fifty (150) questionnaires were distributed to maintenance personnel of the federal and state agencies, consultants and contractors involved in bridges maintenance practice only.

In all, a total of ninety-two (92) valid questionnaires were retrieved from the survey representing $61.33 \%$ effective response rate.

\subsubsection{Characteristics of Respondents}

\section{Type of Respondents}

The frequency for the survey is as follows: thirty-two (32) form the response from maintenance personnel representing $34.78 \%$, thirty-six (36) form response from consultants representing $39.13 \%$, and twenty-four (24) form response from contractors representing $26.09 \%$.

Distribution of data collection on respondents' type/status involved in bridges maintenance practice shows reasonable response from each category of respondents. This is because each category of respondents' response forms more than $50 \%$ of questionnaire they receive

\section{Academic Qualifications of the Respondents}

The respondents' qualification is as follows: respondents with Ordinary National diploma (OND) form 13.04\%, respondents with Higher National Diploma (HND) form $36.96 \%$, respondents' with Bachelor of Science (BSc/
B.Eng.) form $21.97 \%$, respondents with Masters of Science (MSc) form 25\% and respondents with Doctor of Philosophy $(\mathrm{PhD})$ form $4.35 \%$. That shows majority of the respondents have reasonable academic qualifications and this would authenticate the reliability and validity of data obtained from the survey.

\section{Respondents' Experience in Bridges Maintenance Business:}

The distribution of data collection on respondents' experience is as follows: 5-15years form $56.52 \%$. 16-25years form $31.52 \%$, 26-35years form $11.96 \%$. Survey on respondents' experience shows that majority of them are highly experienced in the construction industry which would also authenticate the validity and reliability of data obtained from the field.

\subsubsection{Determining the Suitable Measures that Enhance Bridges Maintenance Practice}

To determine the suitable measures that enhance bridges maintenance practice, the measures identified in literature were examined. The suitability of each measure was determined using the criteria established and discussed earlier. The assessment of the BMM was done based on the respective bridge maintenance factors. The results of the assessment are provided below.

The rating scales for mean values are as follows: $0-1.49=$ Not Suitable (NS), 1.5-2.4= Least Suitable (LS), 2.5-3.4= Fairly Suitable (FS), 3.5-4.4= Suitable (S), 4.5-5.00= Highly Suitable (HS)

Table 3. Preliminary considerations based measures

\begin{tabular}{|c|c|c|c|c|c|}
\hline S/No. & Bridges maintenance measures & Mean & Std. Deviation & Ranking & Remarks \\
\hline 1 & Inventory & 4.047619 & 1.395571226 & 1 & $\mathrm{~S}$ \\
\hline 2 & Condition, need and damage assessments & 4 & 1 & 2 & $\mathrm{~S}$ \\
\hline 3 & Reliability and technical feasibility & 4 & 1.076055174 & 2 & $\mathrm{~S}$ \\
\hline 4 & Funding and allocation & 3.952381 & 1.283596139 & 3 & $\mathrm{~S}$ \\
\hline 5 & Scheduling and programming & 3.8095238 & 1.249761882 & 4 & $\mathrm{~S}$ \\
\hline 6 & Considerations of risks involved with any damages in safety & 3.75 & 1.482352327 & 5 & $\mathrm{~S}$ \\
\hline 7 & Assessment of life expectancy for various options & 3.6 & 1.142481141 & 6 & $\mathrm{~S}$ \\
\hline 8 & Considering availability and efficacy of repair materials \& equipment & 3.5714286 & 1.207121724 & 7 & $\mathrm{~S}$ \\
\hline 9 & Feasibility of having long duration trafic blocks & 3.45 & 1.099042646 & 8 & FS \\
\hline 10 & Assessment of estimated remaining life of structure & 3.3809524 & 1.359271514 & 9 & FS \\
\hline
\end{tabular}

0-1.49= Not Suitable (NS), 1.5-2.4= Least Suitable (LS), 2.5-3.4= Fairly Suitable (FS), 3.5-4.4= Suitable (S), 4.5-5.00 = Highly Suitable (HS)

Table 4. Bridge investment based measures

\begin{tabular}{|c|l|c|c|c|c|}
\hline S/No. & \multicolumn{1}{|c|}{ Bridges maintenance measures } & Mean & Std. Deviation & Ranking & Remarks \\
\hline 1 & Cost of repairs/rehabilitation for both short term and long term & 4 & 1.140175425 & 1 & S \\
\hline 2 & Determination of funding requirements to meets performance targets & 3.8571429 & 1.108409414 & 2 & S \\
\hline 3 & Documents agency appropriate projects and to improve accountability & 3.6190476 & 0.973457265 & 3 & S \\
\hline 4 & Using of systems for measuring bridge performance & 3.3809524 & 1.359271514 & 4 & FS \\
\hline 5 & Establishment and usage of performance measures for benchmarking & 3.2857143 & 1.346954236 & 5 & FS \\
\hline
\end{tabular}

0-1.49= Not Suitable (NS), 1.5-2.4= Least Suitable (LS), 2.5-3.4= Fairly Suitable (FS), 3.5-4.4= Suitable (S), 4.5-5.00 = Highly Suitable (HS) 
Table 5. Bridge preservation based measures

\begin{tabular}{|c|c|c|c|c|c|}
\hline S/No. & Bridges maintenance measures & Mean & $\begin{array}{c}\text { Std. } \\
\text { Deviation }\end{array}$ & Ranking & Remarks \\
\hline 1 & Laying of temporary diversion and access for repairs & 4.0952381 & 0.889087279 & 1 & $\mathrm{~S}$ \\
\hline 2 & Tracking of bridge-level work recommended actions as part of inspections & 3.7619048 & 0.889087279 & 2 & $\mathrm{~S}$ \\
\hline 3 & Inspection of bridges at the elements level & 3.7619048 & 1.48002574 & 3 & S \\
\hline 4 & Setting of programms for common types of preservation actions & 3.75 & 1.251315098 & 4 & $\mathrm{~S}$ \\
\hline 5 & Tracking and prioritizing rehabilitation and replacement work & 3.5 & 1.235441536 & 5 & $\mathrm{~S}$ \\
\hline
\end{tabular}

0-1.49= Not Suitable (NS), 1.5-2.4= Least Suitable (LS), 2.5-3.4= Fairly Suitable (FS), 3.5-4.4= Suitable (S), 4.5-5.00 = Highly Suitable (HS)

Table 6. Construct maintenance based measures

\begin{tabular}{|c|c|c|c|c|c|}
\hline S/No. & Bridges maintenance measures & Mean & Std. Deviation & Ranking & Remarks \\
\hline 1 & Enhancing load capacity & 4.1 & 1.252631579 & 1 & $\mathrm{~S}$ \\
\hline 2 & Establishment of the level and frequency of maintenance & 3.952381 & 1.547619048 & 2 & $\mathrm{~S}$ \\
\hline 3 & Enhancing communications between bridges design and maintenance & 3.8571429 & 1.628571429 & 3 & $\mathrm{~S}$ \\
\hline 4 & Usage of reporting bridge management systems & 3.8571429 & 1.128571429 & 3 & $\mathrm{~S}$ \\
\hline 5 & Availability of expert supervision during implementation & 3.8 & 2.168421053 & 4 & $\mathrm{~S}$ \\
\hline 6 & Use of standard designs-institutionalizing maintainable bridges design & 3.6666667 & 1.433333333 & 5 & $\mathrm{~S}$ \\
\hline 7 & Adoption of proven technology and new ideas & 3.6 & 2.042105263 & 6 & $\mathrm{~S}$ \\
\hline 8 & Alternative contracting and delivery approaches such design/build & 3.4761905 & 1.261904762 & 7 & FS \\
\hline 9 & Using of resilient techniques and materials to environmental changes & 3.4 & 2.252631579 & 8 & FS \\
\hline 10 & Discouraging of the use of high maintenance design details & 3.1904762 & 1.461904762 & 9 & FS \\
\hline 11 & Employing automated visual inspection & 3.1904762 & 1.761904762 & 9 & FS \\
\hline 12 & Using of robust techniques in implementing maintenance plans & 3.15 & 2.45 & 10 & FS \\
\hline
\end{tabular}

0-1.49= Not Suitable (NS), 1.5-2.4= Least Suitable (LS), 2.5-3.4= Fairly Suitable (FS), 3.5-4.4= Suitable (S), 4.5-5.00 = Highly Suitable (HS)

\subsection{Testing Respondents' Extent of Differences on the Level of Application and Suitability of the Measures Established}

To test whether significant differences exist in terms of the opinions of the respondents regarding the criticality or otherwise of the success factors, Analysis of variances (ANOVA) was employed. The study assumed a normally distributed sample. The ANOVA test results was interpreted using the following: a. If P-value is 0.05 and above, this implies that there is a Significant Difference (SDf) in ranking among respondents. In a nutshell, the ranking is in disagreement

b. If P-value is $<0.05$, this implies that there is No Significant (NS) difference in ranking between or among respondents. In a nutshell, the ranking is in agreement

The test was conducted on each of the groups of the critical success factors established. The results are presented in Table 7. 
Table 7. Respondents' extent of differences on the suitability of the measures established

\begin{tabular}{|c|c|c|c|}
\hline A. & Preliminary considerations & & \\
\hline S/No. & Bridges maintenance measures & P-value & Remarks \\
\hline 1 & Inventory & 0.1638645 & SDf \\
\hline 2 & Condition, need and damage assessments & 0.6883692 & SDf \\
\hline 3 & Reliability and technical feasibility & 0.3936737 & SDf \\
\hline 4 & Funding and allocation & 0.8046028 & SDf \\
\hline 5 & Scheduling and programming & 0.4644544 & SDf \\
\hline 6 & Assessment of estimated remaining life of structure & 0.4691671 & SDf \\
\hline 7 & Assessment of life expectancy for various options & 0.8977034 & SDf \\
\hline 8 & Considerations of risks involved with any damages in safety & 0.6378029 & SDf \\
\hline 9 & Considering availability and efficacy of repair materials \& equipment & 0.7612775 & SDf \\
\hline 10 & Feasibility of having long duration traffic blocks & 0.8357021 & SDf \\
\hline B. & Making the case for bridge investment & & \\
\hline S/No. & Bridges maintenance measures & P-value & Remarks \\
\hline 1 & Determination of funding requirements to meet performance targets & 0.6518829 & SDf \\
\hline 2 & Cost of repairs/rehabilitation for both short term and long term & 0.716764 & SDf \\
\hline 3 & Documents agency appropriate projects and to improve accountability & 0.895865 & SDf \\
\hline 4 & Using of systems for measuring bridge performance & 0.2376912 & SDf \\
\hline 5 & Establishment and usage of performance measures for benchmarking & 0.4113114 & SDf \\
\hline C. & Bridge preservation & & \\
\hline S/No. & Bridges maintenance measures & P-value & Remarks \\
\hline 1 & Inspection of bridges at the elements level & 0.2531578 & SDf \\
\hline 2 & Laying of temporary diversion and access for repairs & 0.5455966 & SDf \\
\hline 3 & Tracking of bridge-level work recommended actions as part of inspections & 0.6072923 & SDf \\
\hline 4 & Tracking and prioritizing rehabilitation and replacement work & 0.7406909 & SDf \\
\hline 5 & Setting of programms for common types of preservation actions & 0.740325 & SDf \\
\hline D. & Construct maintenance bridges & & \\
\hline S/No. & Bridges maintenance measures & P-value & Remarks \\
\hline 1 & Establishment of the level and frequency of maintenance & 0.8643513 & SDf \\
\hline 2 & Enhancing load capacity & 0.7883665 & SDf \\
\hline 3 & Usage of reporting bridge management systems & 0.2627475 & SDf \\
\hline 4 & Availability of expert supervision during implementation & 0.2042796 & SDf \\
\hline 5 & Using of robust techniques in implementing maintenance plans & 0.2286043 & SDf \\
\hline 6 & Using of resilient techniques and materials to environmental changes & 0.7019878 & SDf \\
\hline 7 & Employing automated visual inspection & 0.2780613 & SDf \\
\hline 8 & Adoption of proven technology and new ideas & 0.5694903 & SDf \\
\hline 9 & Discouraging of the use of high maintenance design details & 0.8108513 & SDf \\
\hline 10 & Use of standard designs-institutionalizing maintainable bridges design & 0.8600167 & SDf \\
\hline 11 & Alternative contracting and delivery approaches such design/build & 0.7199888 & SDf \\
\hline 12 & Enhancing communications between bridges design and maintenance & 0.5968538 & SDf \\
\hline
\end{tabular}

Interpretation of P-values: Significant Difference $=$ SDf, No Significant Difference $=$ ND 


\subsection{Discussion of Findings}

\subsubsection{Preliminary Considerations}

The results show that the suitability of the measures that enhance bridge maintenance practice. The following measures: Inventory, condition, need and damage assessments and reliability and technical feasibility and funding and allocation, scheduling and programming, considerations of risks involved with any damages in safety, assessment of life expectancy for various options considering availability and efficacy of repair materials \& equipment are considered suitable measures in enhancing bridges maintenance practice. This is because ratings on the suitability of those measures are within the range of $3.5-$ 4.4 .

However, the respondents considered the two remaining measures as fairly suitable because their ratings are within mean values of 2.5-3.4. These measures are feasibility of having long duration traffic blocks and assessment of estimated remaining life of structure

\subsubsection{Bridge Investment}

The results show that the suitability of the measures that enhance bridge maintenance practice. The results show that the following measures: cost of repairs/rehabilitation for both short term and long term, determination of funding requirements to meets performance targets, documents agency appropriate projects and to improve accountability are considered suitable measures in enhancing bridges maintenance practice. This is because ratings on the suitability of those measures are within the range of $3.5-$ 4.4. However, the respondents considered all the remaining measures as fairly suitable because their ratings are within mean values of 2.5-3.4. These are; using of systems for measuring bridge performance and establishment and usage of performance measures for benchmarking.

\subsubsection{Bridge Preservation}

The results show that the suitability of the measures that enhance bridge maintenance practice. The following measures: laying of temporary diversion and access for repairs, tracking of bridge-level work recommended actions as part of inspections, inspection of bridges at the elements level, setting of programms for common types of preservation actions with and tracking and prioritizing rehabilitation and replacement work are considered suitable measures in enhancing bridges maintenance practice. This is because ratings on the suitability of those measures are within the range of $3.5-4.4$.

\subsubsection{Construct Maintenance}

The results show that the suitability of the measures that enhance bridge maintenance practice. The following measures: enhancing load capacity, establishment of the level and frequency of maintenance, enhancing communications between bridges design and maintenance, usage of reporting bridge management systems, availability of expert supervision during implementation, use of standard designs-institutionalizing maintainable bridges design and adoption of proven technology and new ideas are considered suitable measures in enhancing bridges maintenance practice. This is because ratings on the suitability of those measures are within the range of $3.5-4.4$. But the respondents considered all the remaining measures in Table 6 as fairly suitable because their ratings are within mean values of 2.5-3.4.

The results determined in this study show that all the measures are suitable in enhancing bridges maintenance, and that conform to assertions by (Ahmad, 2010; Fredericks, 2016; Indian Railways Publication, 2016; Hampshire County, 2015; United States Department of Transportation Publication, 2008; The IABMAS Bridge Management Commission, 2014; United Stated of Transportation Publication, 2012; Federal Highway Administration (FHWA) Publication, 2016). This is because the fore goings assert that all the measures determined in this study enhance bridges maintenance practice.

The results on test of ANOVA on suitability of the measures enhancing bridges maintenance practice have disagreement on all the measures in this category. Their divergent views are attributed to their status.

\subsection{Additional Comments by Respondents}

a. It is important to understand clearly how components such as deck, substructure, superstructure deteriorating existing bridges.

b. It is also important to take into consideration the embankments soil due to erosion.

\subsection{Suggested Measures by Respondents}

a. Effective supervision during construction.

b. Regular inspection to check

c. Determination of number of vehicles to use for the maintenance.

d. Engagement of experts in bridges construction.

e. The should be periodic survey and inspection to avoid failure.

f. Annual cleaning and flushing of drains, pier caps, abutment seats, concrete rails etc.

g. Collaboration among the key stakeholders engaged in bridge maintenance.

h. Using the right tools and equipment for bridges maintenance

i. There should be adequate designs, standard materials to be used in the execution of bridges work.

\section{Conclusion and Recommendations}

\subsection{Conclusion}

The study determined the suitable measures that enhance bridge maintenance to include: condition, need and damage assessments and reliability and technical feasibility and funding and allocation, cost of repairs/rehabilitation for both short term and long term, determination of funding 
requirements to meets performance targets, documents agency appropriate projects and to improve accountability among others.

\subsection{Recommendations}

a. Adopting the suitable measures determined in this study would enhance bridge maintenance practice towards achieving outstanding results.

b. There should be an effective collaboration among the key stakeholders in bridges maintenance works.

c. Roads and bridges maintenance key stakeholders (state and federal agencies, consultants and contractors) should embraced the suitable measures determined in this study for policy formulation in this sector.

\subsection{Recommended Area for Further Studies}

Subsequent work in this subject area should determine more measures, and use them (the determined measures) to develop a framework that could be used for efficient bridge maintenance practice.

\section{REFERENCES}

[1] Abdel-Qader, I., Abudayyeh, O. \& Kelly, M.E. (2003). Analysis of Edge-Detection Techniques for Crack Identification in Bridges. Journal of Computing in Civil Engineering. 17 (4). p.pp. 255-263.

[2] Abdel-Qader, I., Pashaie-Rad, S., Abudayyeh, O. \& Yehia, S. (2006). PCA-Based algorithm for unsupervised bridge crack detection. Advances in Engineering Software. 37 (12). p.pp. 771-778.

[3] Abdullahi, M. (2014). Assessing contractors' cash flow forecasting process capability in Nigeria an unpublished MSc dissertation submitted to the Department of Quantity Surveying, Ahmadu Bello University Zaria, Nigeria.

[4] Abramowitz M and Stegun I.A (1972). Handbook of Mathematical Functions with Formulas, Graphs and Mathematical Tables. 9th edition, New York: Wiley.

[5] Adhikari, R.S., Moselhi, O. \& Bagchi, A. (2013). A study of image-based element condition index for bridge inspection. In: 30th ISARC, Montréal, Canada. 2013, pp. 345-356.

[6] Adhikari, R.S., Moselhi, O. \& Bagchi, A. (2012). Automated prediction of condition state rating in bridge inspection. Geron technology. 11 (2).

[7] Adhikari, R.S., Moselhi, O. \& Bagchi, A. (2014). Image-based retrieval of concrete crack properties for bridge inspection. Automation in Construction. 39. p.pp. 180-194.

[8] Ahmad, A. S. (2010). Bridge Performance Measures (BPM). US Department of Transportation, Federal Highway Administration, Detroit, Michigan

[9] Arena, A., Delle Piane, C. \& Sarout, J. (2014). A new computational approach to cracks quantification from 2D image analysis: Application to micro-cracks description in rocks. Computers \& Geosciences. 66. p.pp. 106-120.
[10] ASCE (2013). 2013 Report Card for America's Infrastructure: Bridges.

[11] Bechtel-U.S. Council for International Business (2014). Submission to the United Nations Sustainable Development Goals

[12] Belsky, M., Sacks, R. and Brilakis, I. (2013). A Framework for Semantic Enrichment of IFC Building Models. In: Proceedings of the CIB W78 2013: 30th International Conference. 2013, 9-12 October 2013, Beijing, China, pp. 514-523.

[13] Brilakis, I., Lourakis, M., Sacks, R., Savarese, S., Christodoulou, S., Teizer, J. \& Makhmalbaf, A. (2010). Toward automated generation of parametric BIMs based on hybrid video and laser scanning data. Advanced 56 Engineering Informatics. 24 (4). p.pp. 456-465.

[14] Chen, P.-H., Shen, H.-K., Lei, C.-Y. \& Chang, L.-M. (2012). Support-vector-machine-based method for automated steel bridge rust assessment. Automation in Construction. 23. p.pp. 9-19.

[15] Chen, S. (2012). Laser Scanning Technology for Bridge Monitoring. INTECH Open Access Publisher.

[16] Chen, Y.C., Kang, S.C. \& Yang, C.E. (2011). A lightweight imaged based bridge inspection system using fishing pole, fishing line and fisheye camera. In: Proceedings of $28^{\text {th }}$ International Symposium on Automation and Robotics in Construction (ISARC). 2011, pp. 813-817.

[17] Cheng, H.D., Shi, X.J. \& Glazier, C. (2003). Real-Time Image Thresholding Based on Sample Space Reduction and Interpolation Approach. Journal of Computing in Civil Engineering. 17 (4). p.pp. 264-272.

[18] Cheung, K.C, Mooi, L.C. (1994). A Comparison between the rating scale model and dual scaling for Likert scales'.

[19] Chima, O., and Ekeghe, N. (2017). Filling Nigeria's Infrastructure Gap Online materials: ICRC Media \& Publicity Unit News

[20] Cochran J.K (1997). Organizational research for determining appropriate sample size in survey Research. Wiley online. https://www.wiley.com> en-us

[21] Daum, S. \& Borrmann, A. (2013). Processing of Topological BIM Queries using Boundary Representation Based Methods. Advanced Engineering Informatics. 28 (4). p.pp. 272-286.

[22] Department for Transport and Highways Agency (2014). Maintaining Strategic Infrastructure: Roads. Department of Transport (2012). Bridge Inspection Competence and Training Phase 2 Training Manual.

[23] Dietenbeck, T., Othmani, A., Attene, M., Favreau, J., Dietenbeck, T., Othmani, A., Attene, M. \& Framework, J.F.A (2015). A Framework for Mesh Segmentation and Annotation using Ontologies. 15ème conference international sur l'extraction et la gestion des connaissance (EGC 2015).

[24] Esser, B., Pelczarski, N., Huston, D. \& Arms, S. (2000). Wireless Inductive Robotic Inspection of Structures. In: Proceedings of the IASTED International Conference Robotics and Applications. 2000.

[25] Federal Highway Administration Research and Technology (2005). Dynamic Bridge Substructure Evaluation and Monitoring. Coordinating, Developing, and Delivering Highway Transportation Innovations. Evaluation and Monitoring Publication Number: FHWA-RD-03-089 
[26] Fellows, R and Liu, A (1999). Research methods for construction. Blackwell science ltd.

[27] Fernandes, R.P.L. (2013). Advantages and Disadvantages of BIM Platforms on Construction Site. Master Thesis.

[28] Field, A. (2005). Discovering statistics using SPSS for windows, sage publications, London. Engineering and Management D. L: 1061/ (ASCE) 0733-9364. 130: (691).

[29] Fredericks, D. (2016). Importance of Bridge Preventive Maintenance Plans. Structures loads at PSOmas) PSOmas insight. OnlineGaus, J. (2012). Bridge Inspection Safety Discussion.

[30] German, S., Brilakis, I. \& DesRoches, R. (2012). Rapid entropy-based detection and properties measurement of concrete spalling with machine vision for post-earthquake safety assessments. Advanced Engineering Informatics. 26 (4). p.pp. 846-858.

[31] German, S., Jeon, J.-S., Zhu, Z., Bearman, C., Brilakis, I., DesRoches, R. \& Lowes, L. (2013). Machine Vision-Enhanced Postearthquake Inspection. Journal of Computing in Civil Engineering. p.pp. 622-634.

[32] Guldur, B. \& Hajjar, J.F. (2014). Laser-based structural sensing and surface damage detection.

[33] Haardt, P (2002). Development of a Bridge Management System for the Germany Highway Network (IABMAS, Barcelona, Spain

[34] Hampshire County Council (2015). Inspection of Highway Structures. [Online]. 26 June 2015. Available from: http://www3.hants.gov.uk/roads/highwayspolicy/structures/structures-inspections.htm. [Accessed: 26 June 2015].

[35] Hearn, G., Purvis, R. L., Thompson, P., Bushman, W. H., Mcghee, K. K. and Mckeel, W. T. (2010). Bridge Maintenance and Management: A Look to the Future. Virginia Transportation Research Council

[36] Hichri, N., Stefani, C., De Luca, L., Veron, P. \& Hamon, G. (2013). From point cloud to BIM: A survey of existing approaches. International Archives of the Photogrammetry, Remote Sensing and Spatial Information Sciences. XL (September). p.pp. 343-348.

[37] Hughes, C.L. (2004). Quantitative and qualitative approaches. Department of Sociology University of Warwick, CV4 7AL United Kingdom.

[38] Hüthwohl, P., Lu, R., and Brilakis, I. (2018). Challenges of bridge maintenance inspection University of Cambridge, UK. Email: ib340@cam.ac.uk (PDF Download Available

[39] HyD (2005). "Facts of Highways", Highways Department (HyD) of HKSAR.<http://www.hyd.gov.hk/eng/public/publi cations/factsheet/doc/factsheet.pdf $>$ (accessed in April 2006).

[40] HyD (2006), "Brief introduction to structure maintenance works of regional offices" Notes at presentation to HKU research team, HyD of HKSAR.

[41] Kim, C., Lee, J., Cho, M. \& Kim, C. (2011). Fully Automated Registration of 3D CAD Model with Point Cloud from Construction Site. Proceedings of the International Symposium on Automation and Robotics in Construction (ISARC). p.pp. 917-922.

[42] Koch, C., Paal, S.G., Rashidi, A., Zhu, Z., König, M. \& Brilakis, I. (2014). Achievements and Challenges in Machine
Vision-Based Inspection of Large Concrete Structures. Advances in Structural Engineering. 17 (3). p.pp. 303-318.

[43] Koppula, H.S., Anand, A., Joachims, T. \& Saxena, A. (2011). Semantic Labeling of 3D Point Clouds for Indoor Scenes. Neural Information Processing Systems. p.pp. 1-9.

[44] Landau, S and Everett, B.S (2004). A hand book of statistical analyses using SPSS. Chapman And Hall/CRC Press company, Washington D.C

[45] Lee, J.H., Lee, J.M., Kim, H.J. \& Moon, Y.S. (2008). Machine Vision System for Automatic Inspection of Bridges. In: 2008 Congress on Image and Signal Processing. 2008, IEEE, pp. 363-366.

[46] Levy, P and Lemeshow, S (2008). Sampling of populations: methods and applications. $4^{\text {th }}$ edition. Wiley series in survey methodology. $\quad$ ISBN: $978-0-470$ 040072 .https://www.wiley.com> en-us

[47] Li, G., He, S., Ju, Y. \& Du, K. (2014). Long-distance precision inspection method for bridge cracks with image processing. Automation in Construction. 41. p.pp. 83-95.

[48] London Bridges Engineering Group (2010). Bridge Condition Indicators Project.

[49] London Bridges Engineering Group (2008). Phase 1 Maintenance Prioritisation for Highway Structures.

[50] London Underground (2014). S1060 Civil Engineering Bridges and Structures Inspection Standard.

[51] Matsumoto, M. (2013). Bridge Assessment Methods Using Image Processing and Infrared hermography Technology.

[52] Matsumoto, M., Mitani, K. \& Catbas, F.N. (2012). Bridge Assessment Methods using Image Processing and Infrared Thermography Technology.

[53] McKinsey \& Company (2011). Keeping Britain moving: The United Kingdom's transport infrastructure needs.

[54] McRobbie, S. (2009). Automated inspection of highway structures 2008/09 - PPR412.

[55] McRobbie, S., Woodward, R. \& Wright, A. (2011). Visualisation and display of automated bridge inspection results - PPR530. Visualisation and display of automated bridge inspection results. 1 (1). p.pp. 1-28.

[56] Moore, M., Phares, B., Graybea, B., Rolander, D. \& Washer, G. (2001). Reliability of Visual Inspection for Highway Bridges, Volume I: Final Report and Volume Ii: Appendices. Baystate Roads Program Local Technical Assistance Program - Tech Note \#31. I (June). p.pp. 1-4.

[57] Nepal, M.P., Staub-French, S., Pottinger, R. \& Webster, A. (2012). Querying a building information model for construction-specific spatial information. Advanced Engineering Informatics. 26 (4). p.pp. 904-923. 57

[58] Nguyen, T.H., Oloufa, A. a. \& Nassar, K. (2005). Algorithms for automated deduction of topological information. Automation in Construction. 14 (1). p.pp. 59-70.

[59] Nishimura, S., Kimoto, K., Abe, A. \& Okazawa, T. (2012). Development of a hybrid camera system for bridge inspection. p.pp. 2197-2203.

[60] Oh, J.-K., Jang, G., Lee, H., Oh, S.M., Lee, S.-C., Choi, Y., Yi, B.-J., Yang, H.W., Lee, J.H. \& Moon, Y.S. (2008). Robotic System for Searching Cracks beneath Bridge. In: 5th International Conference on Ubiquitous Robots and Ambient 
Intelligence (URAI2008). 2008.

[61] Oh, J.-K., Jang, G., Oh, S., Lee, J.H., Yi, B.-J., Moon, Y.S., Lee, J.S. \& Choi, Y. (2009). Bridge inspection robot system with machine vision. Automation in Construction. 18 (7). p.pp. 929-941.

[62] Okorn, B., Xiong, X., Akinci, B. \& Huber, D. (2010). Toward Automated Modeling of Floor Plans. Proceedings of the Symposium on 3D Data Processing, Visualization and Transmission. 2.

[63] Paal, S.G., Jeon, J.-S., Brilakis, I. \& DesRoches, R. (2014). Automated Damage Index Estimation of Reinforced Concrete Columns for Post-Earthquake Evaluations. Journal of Structural Engineering.

[64] Pătrăucean, V., Armeni, I., Nahangi, M., Yeung, J., Brilakis, I. \& Haas, C. (2015). State of research in automatic as-built modelling. Advanced Engineering Informatics. 29 (2). p.pp. $162-171$.

[65] Phares, B.M., Washer, G.A., Rolander, D.D., Graybeal, B.A. \& Moore, M. (2004). Routine Highway Bridge Inspection Condition Documentation Accuracy and Reliability. Journal of Bridge Engineering. 9 (4). p.pp. 403-413.

[66] Posner, I., Cummins, M. \& Newman, P. (2009). Fast Probabilistic Labeling of City Maps. Proc. of Robotics: Science and Systems (RSS).

[67] Pu, S. \& Vosselman, G. (2009). Knowledge based reconstruction of building models from terrestrial laser scanning data. ISPRS Journal of Photogrammetry and Remote Sensing. 64 (6). p.pp. 575-584.

[68] Rabbani, T., van den Heuvel, F. a \& Vosselman, G. (2006). Segmentation of point clouds using smoothness constraint. International Archives of Photogrammetry, Remote Sensing and Spatial Information Sciences - Commission V Symposium 'Image Engineering and Vision Metrology'. 36 (5). p.pp. 248-253. Roads Liaison Group (2005). Management of Highway A Code of Practice.

[69] Rashtchi, R. (2014). How to use mathematical equations in your thesis. Current grad students, 512 Tory Building Carleton University 1125 colonel by drive Ottawa, K15 5B6

[70] Rusu, R.B., Blodow, N., Marton, Z.C. \& Beetz, M. (2009). Close-range Scene Segmentation and Reconstruction of 3D Point Cloud Maps for Mobile Manipulation in Human Environments. IEEE/RSJ International Conference on Intelligent Robots and Systems (IROS '09). p.pp. 1-6.

[71] Son, H., Hwang, N., Kim, C. \& Kim, C. (2014). Rapid and automated determination of rusted surface areas of a steel bridge for robotic maintenance systems. Automation in Construction. 42. p.pp. 13-24.

[72] Szeliski, R. (2006). Image Alignment and Stitching: A Tutorial. Foundations and Trends ${ }^{\circledR}$ in Computer Graphics and Vision. 2 (1). p.pp. 1-104.

[73] Tang, P., Akinci, B. \& Garrett, J.H. (2007). Laser Scanning for Bridge Inspection and Management. IABSE Symposium Report. 93. p.pp. 17-24.

[74] The IABMAS Bridge Management Committee (2014). Overview of existing Bridge Management Systems. Trimble
(2014). Faro Focus3D X130 laser scanner.

[75] Transport Research Board (2008). International Bridge and Structure Management, Buffalo New York

[76] U.S. Department of Transportation (2008). Bridge Evaluation Quality Assurance in Europe.

[77] U.S. Department of Transportation (2012). Bridge Inspector's Reference Manual.

[78] Volk, R., Stengel, J. \& Schultmann, F. (2014). Building Information Modeling (BIM) for existing buildings Literature review and future needs. Automation in Construction. 38. p.pp. 109-127.

[79] Wang, C., Cho, Y.K. \& Kim, C. (2015). Automatic BIM component extraction from point clouds of existing buildings for sustainability applications. Automation in Construction. 56. p.pp. 1-13.

[80] Wong P.C., Wong C.Y., and Darby J. (2001), "Bridge Management in Hong Kong: the selection of appropriate techniques", Current and future trends in bridge design construction and maintenance 2: safety, economy, sustainability and aesthetics, proceedings of the international conference organized by the Institution of Civil,Apr. 25-26, Hong Kong, 3-12.

[81] Xiong, X., Adan, A., Akinci, B. \& Huber, D. (2013). Automatic creation of semantically rich $3 \mathrm{D}$ building models from laser scanner data. Automation in Construction. 31. p.pp $325-337$.

[82] Yu, S.-N., Jang, J.-H. \& Han, C.-S. (2007). Auto inspection system using a mobile robot for detecting concrete cracks in a tunnel. Automation in Construction. 16 (3). p.pp. 255-261.

[83] Zhang, G., Vela, P.A. \& Brilakis, I. (2014a). Automatic generation of as-built geometric civil infrastructure models from point cloud data. Computing in Civil and Building Engineering. p.pp. 406-413.

[84] Zhang, W., Zhang, Z., Qi, D. \& Liu, Y. (2014b). Automatic crack detection and classification method for subway tunnel safety monitoring. Sensors (Basel, Switzerland). 14 (10). p.pp. 19307-28.

[85] Zhu, Z. \& Brilakis, I. (2008). Detecting air pockets for architectural concrete quality assessment using visual sensing. Electronic Journal of Information Technology in Construction. 13. p.pp. 86-102.

[86] Zhu, Z. \& Brilakis, I. (2009). Machine vision-based concrete surface quality assessment. Journal of Construction Engineering and Management. 136 (2). p.pp. 210-218.

[87] Zhu, Z. \& Donia, S. (2013). Spatial and visual data fusion for capturing, retrieval, and modeling of as-built building geometry and features. Visualization in Engineering. 1 (1). p.p. 10.

[88] Zhu, Z., German, S. \& Brilakis, I. (2011). Visual retrieval of concrete crack properties for automated post-earthquake structural safety evaluation. Automation in Construction. 20 (7). p.pp. 874-883. 58. 